\title{
Probing Single DNA Molecule Transport Using Fabricated Nanopores
}

\section{Citation}

Chen, Peng, Jiajun Gu, Eric Brandin, Young-Rok Kim, Qiao Wang, and Daniel Branton. 2004. Probing single DNA molecule transport using fabricated nanopores. Nano Letters 4(11): 2293-2298.

\section{Published Version}

http://dx.doi.org/10.1021/n1048654j

\section{Permanent link}

http://nrs.harvard.edu/urn-3:HUL.InstRepos:3109772

\section{Terms of Use}

This article was downloaded from Harvard University's DASH repository, and is made available under the terms and conditions applicable to Other Posted Material, as set forth at http:// nrs.harvard.edu/urn-3:HUL.InstRepos:dash.current.terms-of-use\#LAA

\section{Share Your Story}

The Harvard community has made this article openly available.

Please share how this access benefits you. Submit a story.

Accessibility 


\title{
Probing Single DNA Molecule Transport Using Fabricated Nanopores
}

\author{
Peng Chen,${ }^{\dagger}$ Jiajun Gu, ${ }^{\ddagger}$ Eric Brandin, ${ }^{\dagger}$ Young-Rok Kim, ${ }^{\dagger}$ Qiao Wang,,${ }^{\S}$ and \\ Daniel Branton ${ }^{*, \dagger}$
}

Department of Molecular and Cellular Biology and Division of Engineering \& Applied Sciences, Harvard University, Cambridge, Massachusetts 02138, and Department of

Radio Engineering, Southeast University, Nanjing 210096, P.R. China

Received August 19, 2004; Revised Manuscript Received September 2, 2004

\begin{abstract}
Nanopores can serve as high throughput, single-molecule sensing devices that provide insight into the distribution of static and dynamic molecular activities, properties, or interactions. We have studied double stranded DNA electrophoretic transport dynamics through fabricated nanopores in silicon nitride. A fabricated pore enables us to interrogate a broader range of molecules with a wider range of conditions than can be investigated in a self-assembled protein pore in a lipid membrane.
\end{abstract}

Recent experiments show that a nanopore in a thin insulating membrane separating two ionic solution filled chambers can serve as a single-molecule sensing device that provides insight into the distribution of static and dynamic molecular activities, properties, or interactions. ${ }^{1-5}$ A single-molecule approach makes it possible to explore individual molecular details that cannot be obtained by ensemble-averaged results and the speed and ease with which molecules can be captured and sensed by a nanopore make it possible to achieve very high throughputs and examine a statistically valid sample of the molecular population.

Most nanopore studies have relied on measuring ionic current blockages caused by DNA or RNA translocating through a nanopore formed by the $\alpha$-hemolysin protein in a lipid bilayer. Although $\alpha$-hemolysin self-assembles with remarkable fidelity and reproducibility, the physical, chemical, and electrical properties of this protein nanopore limit the repertoire of experimental possibilities. Whereas the limiting aperture diameter of $1.5 \mathrm{~nm}$ in the $\alpha$-hemolysin channel is just large enough to translocate an unstructured single stranded nucleic acid molecule, the high temperatures or denaturants required to maintain polynucleotides in a single stranded state disrupt the fragile $\alpha$-hemolysin proteinlipid assembly. While translocating molecules through the $\alpha$-hemolysin protein pore has provided a wealth of empirical correlations, a detailed understanding of the signals obtained has been complicated by the complex charge distribution and structure of the channel. ${ }^{6}$ Furthermore, because electrical

* Corresponding author. Telephone: 617-495-2646; Fax: 617-384-7732; e-mail address: dbranton@harvard.edu.

Department of Molecular and Cellular Biology, Harvard University.

$\doteqdot$ Division of Engineering \& Applied Sciences, Harvard University.

$\S$ Southeast University. detection in $\alpha$-hemolysin depends on conduction changes induced by a polymer's presence in the channel's neck, and because this neck is approximately $5 \mathrm{~nm}$ long, ${ }^{7}$ the conductance changes reflect the presence of up to 10-15 nucleotides that span this distance. ${ }^{8}$ Higher resolution work that seeks to sense fewer nucleotides at any one time will probably require other detection modes involving on-board electronics that cannot be supported by a lipid bilayer.

To overcome the limitations of a protein pore in a lipid bilayer, solid-state nanopores have been fabricated to replace or complement protein pores. ${ }^{9-12}$ Here, we present our first study of DNA translocation kinetics in ion beam sculpted nanopores fabricated in $\mathrm{Si}_{3} \mathrm{~N}_{4}$ with surface properties that have been modified by atomic layer deposition of $\mathrm{Al}_{2} \mathrm{O}_{3}$. The $\mathrm{Al}_{2} \mathrm{O}_{3}$ layers improved nanopore performance by reducing electrical noise and enhancing the DNA capture rate, making it possible to observe a large, statistically valid sample of translocation events before nanopore failure. ${ }^{13}$

Nanopores and Nanochannels. DNA translocations were studied with two types of nanostructures: nanopores through a thin membrane or nanochannels through a thicker membrane (Figure 1). The diameters of both the nanopores and nanochannels were $\sim 15 \mathrm{~nm}$. This diameter is much larger than the cross section of a double stranded DNA molecule ( $2.4 \mathrm{~nm}$ ), ensuring free passage of the molecules by minimizing steric or other pore/molecule interactions.

DNA Molecules Are Stretched by the Electrical Field. A recent investigation with ion beam sculpted nanopores has demonstrated that the translocation of a single molecule, which is recorded as a single translocation "event", often 

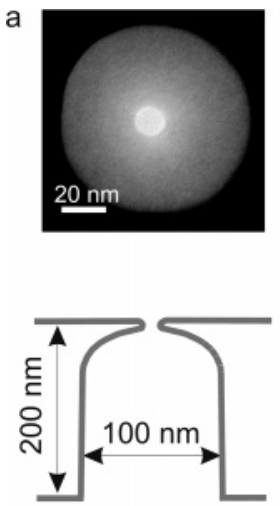

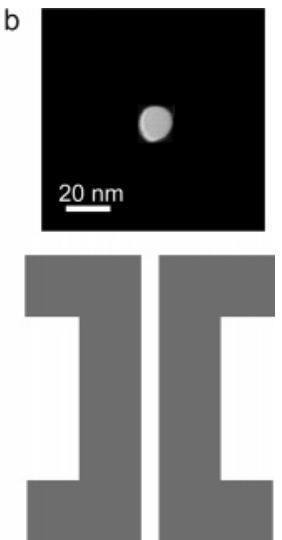

Figure 1. Fabricated nanopores and nanochannels. (a) TEM picture of an ion beam sculpted nanopore with $3 \mathrm{~nm}$ alumina ALD coating (top) and schematic of its cross section (bottom). The $\mathrm{Al}_{2} \mathrm{O}_{3}$ layer is represented in gray. (b) TEM picture of a nanochannel produced from a $\sim 100 \mathrm{~nm}$ FIB pore plus $40 \mathrm{~nm} \mathrm{Al}_{2} \mathrm{O}_{3}$ ALD coating (top) and schematic of its cross section (bottom).

induces current blockades at quantized levels. ${ }^{14}$ To a first order approximation, the current blockage from the regions of the molecule that are translocating through the pore is equivalent to the total ionic current that can be carried by the volume of solution excluded from the pore by the translocating molecule,

$$
I_{\text {block }}=\rho \times A \times V_{\text {bias }} / L_{\text {pore }}
$$

where $\rho$ is the solution conductivity, $V_{\text {bias }}$ the applied voltage, $L_{\text {pore }}$ the effective pore length, and $A$ the hydrodynamic cross section of the translocating molecule. Since the blockade current is linearly proportional to the hydrodynamic cross section of the translocating material, the translocation events exhibiting only one blockade level were interpreted as translocations of a single, double stranded DNA molecule that translocated through the pore in a linear, single-file manner. Events exhibiting two or more quantized blockade levels were interpreted as double stranded DNA that translocated through the pore with portions of the molecule folded on itself, such that two or even three parallel lengths of the double stranded DNA translocated through the pore simultaneously. ${ }^{14}$ This interpretation was supported by the observation that the multiple-level events were, statistically, shorter than the single-level events.

We observed such quantized levels in many of our blockade events using either nanopores (Figure 2a,c) or nanochannels (Figure 2b) and interpret these multiple level events as did $\mathrm{Li}$ et al. ${ }^{14}$ This interpretation was further strengthened by the observation that $\Phi$ X174 circular double stranded DNA always produced blockades at a level approximately equivalent to translocation of two parallel lengths of double stranded DNA (not shown). The blockades indicating translocation of a double stranded DNA molecule that translocated through the pore in a linear, single-file manner were easily distinguished from those that exhibited two or more quantized blockade levels (Figure 2c). Less than $2 \%$ of the translocations were ambiguous or uninterpretable, and such events were excluded from our analysis. a

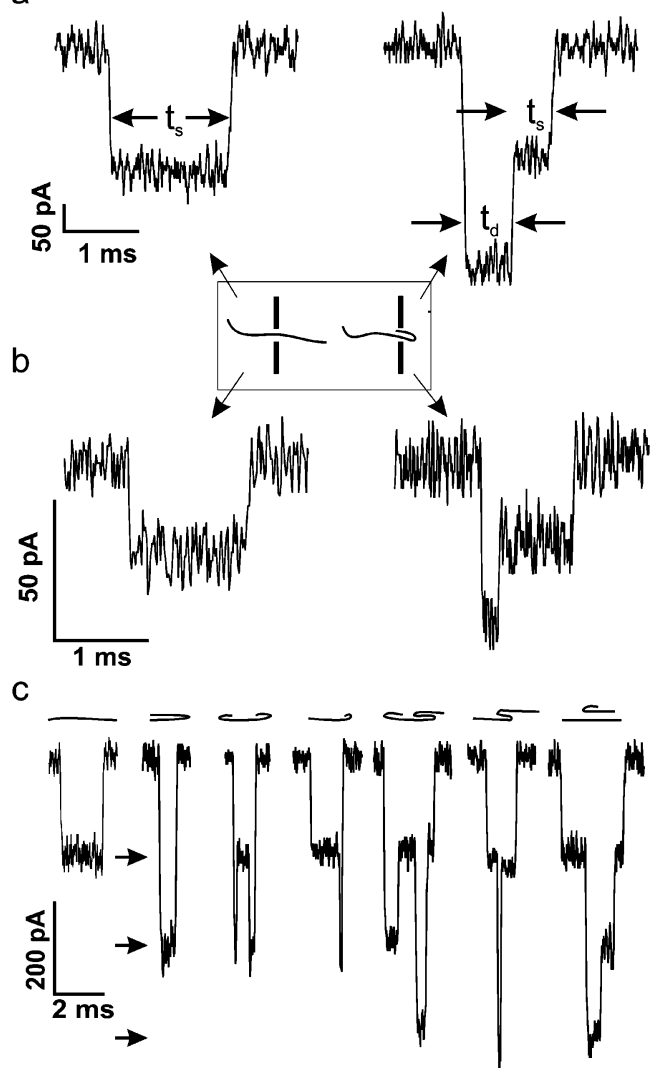

Figure 2. Translocation events. (a) Examples of blockade events produced by $\lambda$ DNA molecules translocating through an ion beam sculpted nanopore (as in Figure 1a) in either strictly single-file order (left, as diagramed in box) or with the leading portion of the molecule folded on itself such that two parallel lengths of the same double stranded DNA translocated through the pore simultaneously (right). (b) Examples of similar blockade events produced by $\lambda$ DNA molecules translocating through a nanochannel fabricated by extensive ALD treatment of a $100 \mathrm{~nm}$ FIB pore (as in Figure 1b). All recordings were taken from a nanopore or nanochannel biased at $200 \mathrm{mV}$, trans side positive. (c) A panel of seven translocation events ( $\lambda$ DNA through a nanopore) to further illustrate our observations and interpretations. The line diagram above each event indicates our interpretation. Arrows indicate the levels corresponding to blockades due to translocation of one, two, or three parallel lengths of DNA. The event at the far right can be interpreted by assuming two DNA molecules translocating simultaneously, but such events were considered ambiguous.

Although we observed multiple levels in many of the blockade events caused by bacteriophage $\lambda$ DNA molecules that were driven through a nanopore by a $200 \mathrm{mV}$ bias, the percentage of multiple level events diminished markedly as the driving bias was increased (Figure 3). Thus, as the voltage bias that attracted the DNA molecules to the nanopore and drove the DNA through this pore was increased, a greater percentage of the molecules must have been completely linearized so as to translocate in a single-file manner.

At thermal equilibrium, the $16.5 \mu \mathrm{m}$ length of $\lambda$ DNA is a flexible molecule that contains $\sim 500$ persistence lengths and therefore forms a random coil with a radius of gyration of approximately $734 \mathrm{~nm}$. The persistence length, which is a measure of the "stiffness" of the wormlike coil, is about $33 \mathrm{~nm}$ or $97 \mathrm{bp}$ in $1 \mathrm{M}$ salt solution. ${ }^{15}$ Hence, to translocate through a $\sim 15 \mathrm{~nm}$ pore, this coiled $\lambda$ DNA must be at least 


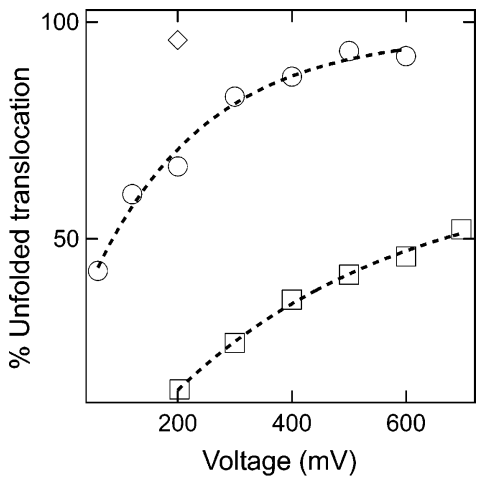

Figure 3. The percentage of unfolded events through ion beam sculpted nanopores increases with applied voltage level and decreases with DNA length. Squares represent the average percentage of single-level events of $\lambda$ DNA through six nanopores. Circles represent the average of $10 \mathrm{kbp}$ DNA through six nanopores. The diamond is the average of $3 \mathrm{kbp}$ DNA through three nanopores. The standard deviation of each point is $<5 \%$. Dashed lines are exponential fitting.

partially linearized. But DNA near a voltage biased pore is not at equilibrium and experiences an inhomogeneous electrical field (the closer to the pore, the stronger the electrical driving force). We explain the observation that greater applied voltages produced a greater percentage of single-level events (Figure 3) by postulating that this inhomogeneous electrical field stretches the DNA toward the pore against the entropic forces that cause it to be randomly coiled at equilibrium. The process may be similar to DNA stretching in nonuniform elongational fluid flows. ${ }^{16}$ This hypothesis is consistent with the observation that short polymers exhibited fewer multiple level events than long polymers (Figure 3).

DNA Electrophoretic Mobility Is Constant Even in the Intense Field of a Biased Nanopore. It is well accepted that, in a comparatively weak field $\left(10^{2} \mathrm{~V} / \mathrm{cm}\right.$ or less), the electrophoretic mobility of $>400$ bp-length DNA in free solution is virtually length- and field-independent because of its free draining property and constant linear charge density. ${ }^{17}$ But despite great interest in the question "...is there new physics when we use ultrahigh fields?", ${ }^{18}$ the constancy of DNA's electrophoretic mobility has not yet been tested in fields of the order of $10^{5} \mathrm{~V} / \mathrm{cm}$. At these high fields, one might anticipate, for instance, electrophoretic retardation due to ion dielectric relaxation, which is a function of polyion velocity and external electrical field, ${ }^{19}$ or counterion decoupling, which can induce mobility increases at high fields. ${ }^{20}$

Although impractical for electrophoresis in macro-sized devices, fields of $2 \times 10^{5} \mathrm{~V} / \mathrm{cm}$ are found in our nanopore system that operates with a bias of $\sim 200 \mathrm{mV}$ across a distance of only $\sim 10^{-6} \mathrm{~cm}$. We therefore determined the mean velocity of DNA (either 48.5, 10, or $3 \mathrm{kbp}$ DNA) translocation versus the applied voltage bias in both nanopores and nanochannels (Figure 4). In these determinations, the multilevel events were mathematically "unfolded" to establish what the translocation time would have been had all of the molecules been linearized and passed through the nanopore in single-file order. More specifically, the corrected translocation time $T=t_{\mathrm{s}}+2 t_{\mathrm{d}}+3 t_{\mathrm{t}} \cdots$, where $t_{\mathrm{s}}$ is the

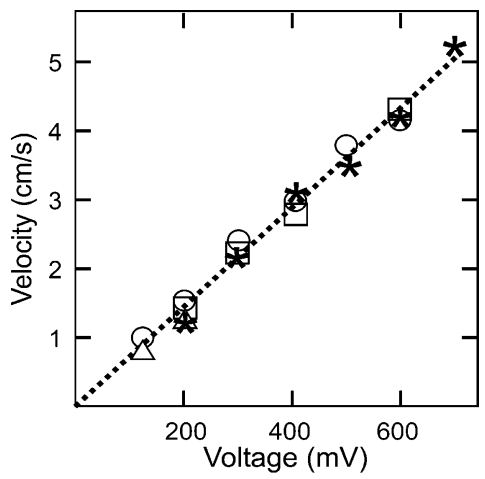

Figure 4. Electrophoretic velocity versus voltage bias. Each data point is the average of 100-1000 translocations. Squares (48.5 kbp $\lambda$ DNA), circles (10 kbp), and diamonds (3 kbp) represent DNA translocation through ion beam sculpted nanopores. Stars represent $\lambda$ DNA translocation through a nanochannel.

duration time for translocation of an unfolded length of double stranded DNA, $t_{\mathrm{d}}$ is the duration time for translocation of a folded region containing two parallel lengths of the same double stranded DNA (see Figure 2), $t_{\mathrm{t}}$ is the duration time for translocation of a folded region containing three parallel lengths of double stranded DNA, if any, and so on. We found that there was no statistical difference between the average time duration of translocation events exhibiting only one blockade level and the corrected translocation time of the mathematically "unfolded" multilevel events. ${ }^{14}$

Plots of the translocation velocity as a function of voltage bias (Figure 4) for the three different length DNA molecules showed that the electrophoretic mobility was independent of voltage and independent of DNA length. The voltage independence of electrophoretic mobility is demonstrated by the evident linear relation between DNA velocity and the driving voltage bias. The length independence of electrophoretic mobility is shown by the fact that the 3,10 , and $48.5 \mathrm{kbp}$ DNAs all traveled at the same velocity and that the three different length DNA molecules all exhibited the same linear velocity/voltage relation. Note also that, although Figure 2 shows that the short pore length of a nanopore produced greater blockades than observed in a long nanochannel, the translocation kinetics were similar in both nanopores and nanochannels (Figure 4). This was expected, as eq 1 shows that $I_{\text {block }}$ is inversely proportional to pore length, whereas the translocation kinetics will be affected mainly by the driving force, which depends on the voltage bias and the DNA charge density. ${ }^{8}$

Although a larger number of different lengths of DNA will have to be assayed to ensure the molecular length independence of mobility in these nanopore systems, our results to date show that electrophoresis through such pores could be used to characterize much longer DNA molecules than can be characterized by gel electrophoresis.

DNA Translocation Kinetics. The translocation time $(T)$ histogram of $10 \mathrm{kbp}$ DNA recorded at $120 \mathrm{mV}$ is depicted in Figure 5a. The mean translocation time, $\langle T\rangle$, corresponded to a velocity of 27 nucleotides/ $\mu$ s, which is $\sim 2$ orders of magnitude faster than single stranded DNA translocation through an $\alpha$-hemolysin pore (for poly dA in $\alpha$-hemolysin, 

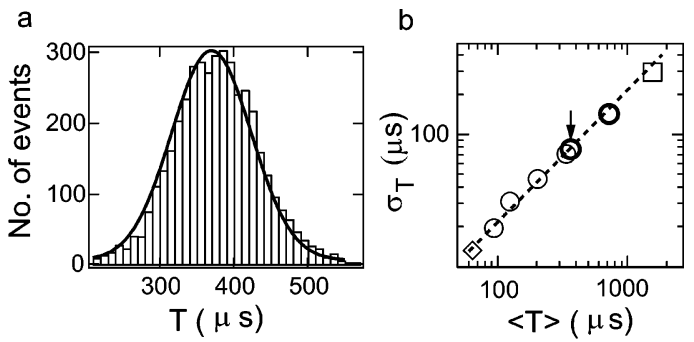

Figure 5. Translocation kinetics in ion beam sculpted nanopores. Each symbol represents statistics of $>2000$ translocation events (except the square, which represents only 212 events of $\lambda$ DNA). (a) The time histogram of $10 \mathrm{kbp}$ DNA translocation events $(n=$ 4247) at $120 \mathrm{mV}$ with a Gaussian fit. It corresponds to the same data point as indicated by an arrow in panel b. (b) The standard deviation $\sigma_{\mathrm{T}}$ of translocation time linearly scales with its mean $\langle T\rangle$. Open circles represent $10 \mathrm{kbp}$ DNA data at 120, 200, 300, and $400 \mathrm{mV}$. Dark circles are $10 \mathrm{kbp}$ DNA data from another pore at $60 \mathrm{mV}$ and $120 \mathrm{mV}$. The diamond and square represent $3 \mathrm{kbp}$ DNA and $\lambda$ DNA (48.5 kbp) at $200 \mathrm{mV}$, respectively. A dashed zerocrossing line is plotted to guide your eyes.

$\sim 0.2$ nucleotides $/ \mu$ s at $120 \mathrm{mV}^{2}$ ). Also in Figure 5a, the translocation times were broadly spread and exhibited a standard deviation of $71 \mu \mathrm{s}$. To completely translocate through a pore, a DNA molecule of length $=L_{\mathrm{DNA}}$ (where $L_{\mathrm{DNA}} \gg$ pore length) must travel an uncertain distance $=$ $L_{\mathrm{DNA}}+\Delta x$ (where $\Delta x$ represents the shift in DNA position due to random walks). This is equivalent to the view that DNA travels a known distance $=L_{\mathrm{DNA}}$, but with a fluctuated velocity $=v+\Delta v$. Thus, the variation of translocation time $T$ can be calculated as $\Delta x / v$. Since $v=L_{\mathrm{DNA}} /\langle T\rangle$, the expected standard deviation of the translocation time would be

$$
\sigma_{\mathrm{T}}=(2 \mathrm{D}\langle T\rangle)^{0.5} / v
$$

or

$$
\sigma_{\mathrm{T}}=(2 \mathrm{D})^{0.5}\langle T\rangle^{1.5} / L_{\mathrm{DNA}}
$$

if we assume normal Brownian diffusion. Taking an experimentally measured diffusion constant of $\mathrm{D} \approx 10^{-8} \mathrm{~cm}^{2} / \mathrm{s}$ for $10 \mathrm{k} \mathrm{bp} \mathrm{DNA}$ in free solution ${ }^{21}$ and the mean value of $T$ in Figure $5 \mathrm{a}$, one would predict $\sigma_{\mathrm{T}} \approx 3 \mu \mathrm{s}$, which is much smaller than the measured standard deviation that was about $71 \mu \mathrm{s}$. This calculation indicates that the time variation of single molecule electrophoresis through a nanopore cannot be explained simply in terms of a driven Brownian random walk.

Interestingly, our experimental data show an unexpected linear relation between the standard deviation of the translocation time versus its mean (Figure 5b). Hence, DNA transport kinetics through a confining narrow pore appears to be a rapid electrophoretic transport perturbed by an anomalous random walk.

DNA Capture Is a Thermal Diffusion-Limited Process. DNA entry into a nanopore depends on two processes. First, the molecule has to diffuse to a region that is close enough

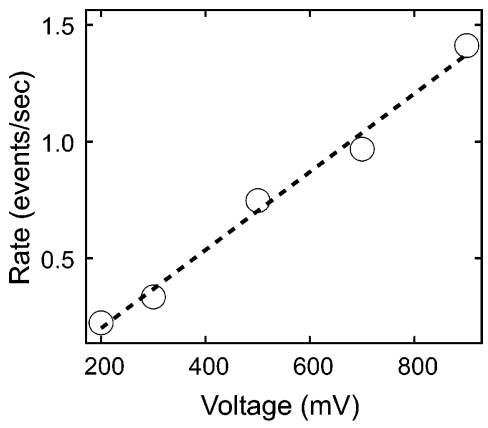

Figure 6. Typical example of the DNA capture and translocation rate as a function of the voltage applied across the nanopore. The measured number of $\lambda$ DNA $(5 \mu \mathrm{g} / \mathrm{mL})$ translocations per second at different voltages are fitted by a line.

to the voltage-biased pore. Second, the strong electrical field near the pore captures the molecule and threads it through the pore..$^{22}$ The capture rate, $R$, of a perfectly absorbing hemisphere of radius $r$ is given by ${ }^{23}$

$$
R=2 \pi C D r
$$

where $D$ is the diffusion constant, $C$ is the molar concentration, and $r$ is the effective radius of the perfectly absorbing hemisphere within which DNA is unlikely to escape, because diffusion is overwhelmed by the electrical attractive force. The capture radius $r$ is linearly proportional to the electrical field and is also a function of the pore radius.

Therefore, as seen in eq 3, if the rate-limiting step is the diffusion into the absorbing region, the rate of DNA capture (measured as the number of DNA molecules that translocated through the pore per unit time) should be linearly proportional to the applied voltage. This is indeed the case in our experimental condition (Figure 6).

The capture radius can be calculated from the measurements using $r=R /(2 \pi C D)$. For example, assuming $D \sim 6$ $\times 10^{-9} \mathrm{~cm}^{2} / \mathrm{s}$ for $\lambda$ DNA, ${ }^{21}$ the calculated $r$ at $500 \mathrm{mV}$ in Figure 6 is about $2.8 \mu \mathrm{m}$, which is much larger than the pore radius of $\sim 7.5 \mathrm{~nm}$. For distances $r$ greater than twice the pore radius $a$, the electrical gradient is $E \approx\left(V_{\text {bias }} a^{2}\right) /$ $\left(2 L_{\text {pore }}\right)\left(r^{2}\right) .{ }^{24}$ This gives $E \approx 7.4 \mathrm{~V} / \mathrm{cm}$ at $r$ in this example, a reasonable bias comparable to the electrical field strength often used to drive DNA in gel electrophoresis.

Direct observation of DNA being captured by and subsequently translocating through a $500 \mathrm{mV}$ biased nanopore using time-resolved fluorescence studies showed that many molecules far from the pore exhibited the expected Brownian motion of DNA in solution. But once molecules diffused into a radius of less than about $3 \mu \mathrm{m}$ from the nanopore, they were very quickly pulled toward the nanopore, whereupon they disappeared from the microscope's field of view as they rapidly translocated through the nanopore. As a consequence, a DNA-depleted region was usually observed within a distance of $<3 \mu \mathrm{m}$ from the nanopore. For example, in the experiment shown in Figure 7, a DNA molecule took $4.4 \mathrm{~s}$ to diffuse a distance of $\sim 7$ $\mu \mathrm{m}$ toward the nanopore (Figure $7 \mathrm{a}$ to Figure $7 \mathrm{~b}$ ), close to the theoretical expectation of $2 \mathrm{~s}$. But once it reached the 


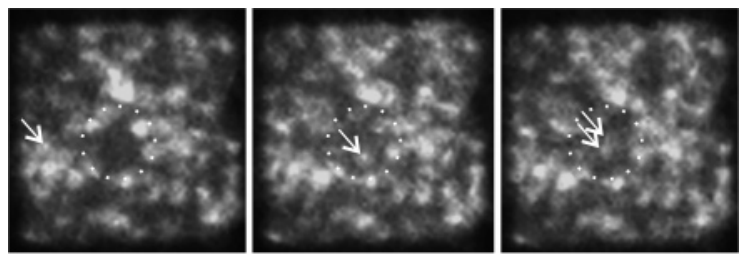

Figure 7. Time-resolved fluorescence study (50 ms resolution) shows distinct phases of DNA diffusion and capture by a biased pore $(500 \mathrm{mV})$. (a) A view of fluorescently labeled DNA molecules on the cis side of a nanopore at time $=0 \mathrm{~ms}$. The capture area surrounding the location of the nanopore (dotted circle) is typically depleted of DNA molecules. One fluorescently labeled molecule whose trajectory can be followed in images $\mathrm{b}$ and $\mathrm{c}$ is indicated by an arrow. (b) The same nanopore $4400 \mathrm{~ms}$ later. The molecule identified by the arrow has slowly diffused into or very near the capture area surrounding the nanopore. (c) At $t=4450 \mathrm{~ms}$, within $50 \mathrm{~ms}$ of the image shown in $\mathrm{b}$, the molecule appears somewhat elongated as it was rapidly captured by, and translocated through, the nanopore. By $t=4500 \mathrm{~ms}$ (not shown) the molecule has disappeared from view and the region around the nanopore again appears depleted of DNA molecules.

electrical absorbing region $(\sim 2.2 \mu \mathrm{m}$ in Figure $7 \mathrm{~b})$, it was actively pulled toward and translocated through the pore in $<50 \mathrm{~ms}$, the temporal resolution of our system (Figure 7c). The "elongated" fluorescence signal seen in Figure 7c is due to DNA's rapid movement as it is stretched toward the nanopore by the proximal voltage bias.

Our results show how a voltage biased solid state nanopore can serve as a high throughput single molecule sensing device. By sequentially bringing charged polymers to a defined interrogation site, the nanopore reports the presence and other properties of each translocating molecule by detecting fluctuations in an abundant number of ions (ca.10 ions/msec at a $200 \mathrm{mV}$ bias across a $15 \mathrm{~nm}$ pore) that traverse the nanopore. The bias across and near the nanopore serves not only to translocate the molecule, but also, as shown here, to linearize the polymer before its entry into the nanopore itself. This linearized, minimum-entropy state is favorable for detecting and assessing the binding of DNA to proteins or the associations of single stranded DNA to other DNA or RNA oligonucleotides.

Our results also show that, even in the intense $\sim 10^{5} \mathrm{~V} / \mathrm{cm}$ fields of a nanopore, DNA's electrophoretic mobility remains independent of field strength and molecular weight or length. In contrast, strong nonlinearity in mobility vs. electric field has been reported in gel electrophoresis, ${ }^{25}$ where the wellknown length dependent mobility of DNA in a gel matrix is the basis for separating and sequencing different lengths of DNA.

Our experiments with several polymers of different length, including $48 \mathrm{kbp} \lambda$ DNA, show that a solid state nanopore can easily capture and translocate very long polymers. Although the capture rate for even longer polymers will be limited by their diffusion into the capture radius around the pore, there is in principle no reason to doubt that much longer DNA, for example 5-10 Mbp polymers, can also be captured and translocated through a nanopore. Since the translocation time of double stranded DNA through a solid state nanopore appears to be linearly dependent on DNA length (Figure 4), nanopores should be able to determine the molecular sizes of such long molecules ( $>5 \mathrm{Mbp}$ ) where the size resolution of gel electrophoresis is poor. It will be critical in this regard to verify the relation between blockade duration and molecular length for a much larger range of DNA molecular weights than examined here. To reduce the large standard deviations that have characterized our translocation experiments and to enhance accurate molecular weight determinations, it will also be important to gain insight into the true source of these deviations. The understanding gained from experiments with a single well-defined nanopore or nanochannel may also help explain the voltage dependent diffusion and anomalous band broadening that has been noted in conventional gel electrophoresis. ${ }^{26-28}$

To further our still evolving appreciation of the detailed dynamics and physics of polymers moving through the confined space of a nanopore, our focus here has answered some very basic questions about double stranded DNA electrophoretic transport dynamics through solid state nanopores. To date, solid state pores have been less reproducible and more easily clogged than self-assembled $\alpha$-hemolysin pores, but their diameters, lengths, and surface properties can be fashioned as required. Furthermore, the solid-state pores can be used in very strong electrical fields and within a broad range of $\mathrm{pHs}$, temperatures, and pressures that would otherwise destroy protein pore and lipid bilayer assembly. They will therefore enable us to interrogate a broader range of molecules in a wider range of conditions than can be investigated in a self-assembled protein pore in a lipid membrane.

Methods. Nanopore Fabrication. Nanopores were fabricated in $25 \mu \mathrm{m} \times 25 \mu \mathrm{m}$, free-standing, stoichiometric, lowpressure, chemical vapor deposited, $\sim 200 \mathrm{~nm}$ thick $\mathrm{Si}_{3} \mathrm{~N}_{4}$ membranes that were supported on a $12 \mathrm{~mm} \times 6 \mathrm{~mm} \times 0.4$ mm N-type, phosphorus doped, silicon substrate (100) frame. One of two different fabrication methods was used. The first method used ion beam sculpting to reduce the diameter of a $\sim 100 \mathrm{~nm}$ FIB-drilled pore to ca. $20 \mathrm{~nm}$, as previously described. ${ }^{9}$ All surfaces of this $\mathrm{Si}_{3} \mathrm{~N}_{4}$ nanopore were subsequently coated with a few layers of $\mathrm{Al}_{2} \mathrm{O}_{3}$ as described ${ }^{13}$ (Figure 1a). The $\mathrm{Al}_{2} \mathrm{O}_{3}$ layers created a homogeneous surface with virtually no net charge at $\mathrm{pH} 8$.

The second method omitted ion beam sculpting and simply used atomic layer deposition to coat all surfaces of a ca. $100 \mathrm{~nm}$ FIB-drilled pore with many layers of $\mathrm{Al}_{2} \mathrm{O}_{3}$. The many layers of $\mathrm{Al}_{2} \mathrm{O}_{3}$ reduced the diameter of a $\sim 100 \mathrm{~nm}$ pore to ca. $15 \mathrm{~nm}$, in effect creating a nanochannel (Figure 1b) with a greater aspect ratio and pore length than the nanopores described above. ${ }^{13}$ In both cases, the final sizes of our pores were determined by transmission electron microscopy.

DNA Molecules. A pUC19 plasmid (New England Biolabs) was cleaved at a single site with SmaI restriction enzyme to produce the blunt-ended linear double stranded 3 kbp DNA. The purity and quantity of the recovered DNA after phenol extraction were assessed by agarose gel electrophoresis and ultraviolet absorbance. KBA, a closed circular $10 \mathrm{kbp}$ DNA plasmid, ${ }^{29}$ was linearized by digestion with 
SmaI and purified after agarose gel electrophoresis using the QIAquick gel extraction kit (QIAGEN) to produce the 10 kbp DNA. Bacteriophage $\lambda$ double stranded DNA and ФX174 RFII DNA were purchased from New England Biolabs. The typical DNA concentration in the cis chamber was $5 \mu \mathrm{g} / \mathrm{mL}$.

Fluorescence Microscopy. $\lambda$ DNA was stained with the intercalating dye YOYO-1 (Molecular Probes, Eugene, OR), keeping the dye-to-base pair ratio at 1:10. The final DNA concentration was $1 \mu \mathrm{g} / \mathrm{mL}$ in $1 \mathrm{M} \mathrm{KCl}$ solution containing $10 \mathrm{mM}$ Tris (pH 8.0) and $1 \mathrm{mM}$ EDTA. The stained DNA molecules were illuminated by a $100 \mathrm{~W}$ mercury arc lamp and observed with a BX51WI upright microscope (Olympus America, Melville, NY) equipped with an Olympus $40 \times$ objective (water immersion, NA 0.8). Fluorescence image sequences were obtained using an intensified charge coupled device camera (ORCA-ER Hamamatsu Photonics) at $50 \mathrm{~ms}$ time intervals.

Nanopore Setup and Data Acquisition. Instrument setup was as previously described. ${ }^{13}$ The DNA solution on top of the nanopore (cis side) was confined either by a chamber made of poly(dimethylsiloxane) or a small glass tube equipped with a grounding $\mathrm{Ag} / \mathrm{AgCl}$ electrode. The circuit was completed by another $\mathrm{Ag} / \mathrm{AgCl}$ electrode in the trans chamber underneath the nanopore chip. All experiments were performed at room temperature and in buffer solution containing $1 \mathrm{M} \mathrm{KCl}, 10 \mathrm{mM}$ Tris- $\mathrm{HCl}$ and $1 \mathrm{mM}$ EDTA at $\mathrm{pH} \mathrm{8.0.} \mathrm{The} \mathrm{current} \mathrm{through} \mathrm{the} \mathrm{nanopore} \mathrm{was} \mathrm{monitored} \mathrm{at}$ a $10 \mu$ s sampling rate with low-pass filtering at $10 \mathrm{kHz}$ using an Axopatch 200B amplifier (Axon Instruments, Foster City, CA). Data analysis was implemented in MATLAB (The Mathworks, Natick, MA) using custom built software routines.

Acknowledgment. This research was supported by National Institutes of Health grant \# RO1 HG02338 to D.B.

\section{References}

(1) Kasianowicz, J. J.; Brandin, E.; Branton, D.; Deamer, D. W. Proc. Natl. Acad. Sci. U.S.A. 1996, 93, 13770.
(2) Meller, A.; Nivon, L.; Brandin, E.; Golovchenko, J.; Branton, D. Proc. Natl. Acad. Sci. U.S.A. 2000, 97, 1079.

(3) Akeson, M.; Branton, D.; Kasianowicz, J. J.; Brandin, E.; Deamer, D. W. Biophys. J. 1999, 77, 3227.

(4) Sauer-Budge, A. F.; Nyamwanda, J. A.; Lubensky, D. K.; Branton, D. Phys. Rev. Lett. 2003, 90, 238101.

(5) Meller, A. J. Phys. Condens. Matter 2003, 15, R581.

(6) Bates, M.; Burns, M.; Meller, A. Biophys. J. 2003, 84, 2366.

(7) Song, L.; Hobaugh, M. R.; Shustak, C.; Cheley, S.; Bayley, H.; Gouaux, J. E. Science 1996, 274, 1859.

(8) Meller, A.; Nivon, L.; Branton, D. Phys. Rev. Lett. 2001, 86, 3435.

(9) Li, J.; Stein, D.; McMullan, C.; Branton, D.; Aziz, M. J.; Golovchenko, J. A. Nature 2001, 412, 166.

(10) Siwy, Z.; Gu, Y.; Spohr, H. A.; Baur, D.; Wolf-Reber, A.; Spohr, R.; Apel, P. Y.; Korchev, Y. E. Europhys. Lett. 2002, 60, 349.

(11) Storm, A. J.; Chen, J. H.; Ling, X. S.; Zandbergen, H. W.; Dekker, C. Nature Materials 2003, 2, 537.

(12) Saleh, O. A.; Sohn, L. L. Nano Lett. 2003, 3, 37.

(13) Chen, P.; Mitsui, T.; Farmer, D. B.; Golovchenko, J.; Gordon, R. G.; Branton, D. Nano Lett. 2004, 4, 133.

(14) Li, J.; Gershow, M.; Stein, D.; Brandin, E.; Golovchenko, J. Nature Materials 2003, 2, 611.

(15) Manning, G. S. Biopolymers 1981, 20, 1751.

(16) Perkins, T. T.; Smith, D. E.; Chu, S. Science 1997, 276, 2016.

(17) Stellwagen, N. C.; Gelfi, C.; Righetti, P. G. Biopolymers 1997, 42, 687.

(18) Slater, G. W.; Desruisseaux, C.; Hubert, S. J.; Mercier, J.; Labrie, J.; Boileau, J.; Tessier, F.; Pepin, M. P. Electrophoresis 2000, 21, 3873.

(19) Allison, S. A.; Wang, H.; Laue, T. M.; Wilson, T. J.; Wooll, J. O. Biophys. J. 1999, 76, 2488.

(20) Netz, R. R. J. Phys. Chem. B 2003, 107, 8208.

(21) Nkodo, A. E.; Garnier, J. M.; Tinland, B.; Ren, H.; Desruisseaux, C.; McCormick, L. C.; Droulin, G.; Slater, G. W. Electrophoresis 2001, 22, 2424.

(22) Meller, A.; Branton, D. Electrophoresis 2002, 23, 2583.

(23) Berg, H. C. Random walks in biology; Princeton Unversity Press: Princeton, 1983.

(24) Nakane, J.; Akeson, M.; Marziali, A. Electrophoresis 2002, 23, 2592.

(25) Lumpkin, O. J.; Dejardin, P.; Zimm, B. H. Biopolymers 1985, 24, 1573.

(26) Borresen, A.-L.; Hovig, E.; Smith-Sorensen, B.; Malkin, D.; Lystad, S.; Andersen, T. I.; Nesland, J. M.; Isselbacher, K. J.; Friend, S. H. Proc. Natl. Acad. Sci. U.S.A. 1991, 88, 8405.

(27) Bumm, L. A.; Arnold, J. J.; Cygan, M. T.; Dunbar, T. D.; Burgin, T. P.; Jones, L. I.; Allara, D. L.; Tour, J. M.; Weiss, P. S. Science 1996, 271, 1705 .

(28) Pernodet, N.; Tinland, B. Biopolymers 1997, 42, 471.

(29) Byers, T. J.; Husain-Chishti, A.; Dubreuil, R. R.; Branton, D.; Goldstein, L. S. B. J. Cell Biol. 1989, 109, 1633.

NL048654J 